\title{
criAtivo: um ambiente hipermídia de autoria colaborativa
}

\author{
Aline de Campos ${ }^{1}$ \\ Adriano Canabarro Teixeira ${ }^{2}$
}

\begin{abstract}
Resumo
Este artigo aborda o processo de construção de um ambiente virtual de característica livre, que através da conceituação teórica dos elementos da Sociedade em Rede visa promover a autoria colaborativa de projetos didáticos multimídia através de processos hipermidiais, buscando constituir-se em uma alternativa a processos de Inclusão Digital baseados no protagonismo e na co-autoria.
\end{abstract}

Palavras-Chave: Autoria Colaborativa, Hipermídia, Inclusão Digital, Ambientes Virtuais de Aprendizagem.

\section{criAtivo: an hypermedia environment of collaborative authorship}

\begin{abstract}
This article approaches the process of construction of a virtual environment with free characteristic, that through the theoretical conceptualization of the elements of the Society in Net it aims at to promote the collaborative authorship of multimedia didactic projects through hypermedia processes, searching to consist in an alternative for processes of Digital Inclusion based in protagonism and the co-authorship.
\end{abstract}

Key-Words: Collaborative Autorship, Hypermedia, Learning Virtual Environment.

\section{Pressupostos teóricos}

Fazemos parte de grandes redes de convivência que, através de suas manifestações, caracterizam a configuração social de uma época. No presente momento, a potencialização das relações sociais se apresenta como um dos elementos de destaque da sociedade contemporânea, reformulando ou estabelecendo novas formas de comunicação e relacionamento.

Definida pelo sociólogo Manuel Castells como Sociedade em Rede, essa dinâmica é baseada no conceito de que "rede é um conjunto de nós interconectados" (1999), conduzindo a um formato onde os indivíduos são, potencialmente, os nós e a sua correlação com outros, uma imensa estrutura reticular aberta, dinâmica, flexível e adaptável, sujeita a "descontrução e reconstrução contínua" (p. 498).

Neste sentido, supõe-se que a cultura contemporânea é uma mescla de inúmeros fatores sociais, econômicos, políticos, artísticos e naturais, em constante construção e modificação ao longo dos anos. Com a revolução da tecnologia digital, outras formas de comunicação, outras vivências e possibilidades de interação e cooperação foram iniciadas, muitas vezes através da reformulação de práticas já convencionais, levando

1 Acadêmica do Curso de Ciência da Computação da Universidade de Passo Fundo. E-mail: alinedecampos@upf.br.

2 Doutor em Informática na Educação PPGIE/UFRGS. Professor Pesquisador do Curso de Ciência da Computação da

Universidade de Passo Fundo. E-mail: teixeira@upf.br

V.4 № 2, Dezembro, 2006 
assim a novas experiências sociais. Essa tendência define o fenômeno da Cibercultura, que não representa um fato recente, tampouco um visionário contexto futurista, mas sim a "cultura contemporânea, marcada pelas tecnologias digitais" (LEMOS, 2003a, p.12).

Em sua essência, a cibercultura busca o rompimento com posturas de passividade e de consumo, autorizando aos indivíduos um envolvimento efetivo na construção de idéias, recepção e emissão de informações e estruturação de conceitos. Segundo Lemos (2003a, p. 22), a cibercultura é regida por leis que podem auxiliar no entendimento das suas manifestações na sociedade atual. A primeira delas, denominada da Reconfiguração, tem como princípio a não substituição ou eliminação total de uma prática já existente, mas sim a adaptação e reformulação de uma ação que pode vir a se potencializar ou modificar em decorrência dos processos em desenvolvimento.

A segunda, da Liberação dos Pólos de Emissão, caracteriza-se pela quebra da centralização gerada pelas mídias de massa, valorizando as expressões sociais contemporâneas e dando vazão a manifestações através de novos e democráticos espaços, ultrapassando as práticas comunicacionais do tipo um-para-todos para uma lógica de comunicação multidirecional.

Por fim, a lei da Conexão Generalizada, evidente na evolução da tecnologia do computador pessoal para o computador em rede e, atualmente, para o computador conectado móvel, faz com que os conceitos de tempo e espaço sejam resignificados, em função da onipresença possibilitada aos indivíduos por conta desta conectividade instituída.

Neste contexto, ganha destaque um outro conceito: o de hipertexto. Também não se trata de algo novo, mas sim de uma mudança no grau de capacidade comunicacional e de interação social, pois segundo Lévy, os "processos sociotécnicos" sempre possuíram uma "forma hipertextual" (1993, p. 25). Assim, sendo a dinâmica do hipertexto inerente às práticas sócio-comunicacionais, parece natural seu imbricamento aos processos permeados pelas tecnologias digitais, uma vez que se criam elos de comunicação e fluxos contínuos de conceitos, significados e idéias, tendo cada indivíduo como elemento de uma rede de interações complexas, dinâmicas e sem limites.

Essas reflexões podem ser aprofundadas a partir das propriedades do hipertexto definidas por Lévy (1993, p. 25), onde foram estabelecidos diferentes pontos que, combinados, dão origem a uma organização que é própria das relações comunicacionais da dinâmica social atual.

O primeiro destes princípios, chamado de Metamorfose, aponta para a existência de uma contínua transformação na rede hipertextual que a mantém sempre em construção, tornando-a, sobretudo, dinâmica, num contexto onde a trama se adapta a fim de dar conta dos diferentes processos que deve suportar, e, ao tempo em que se transforma, transforma também os nós que a compõe.

A partir disso, o princípio da heterogeneidade apresenta que, além de em constante transformação, os "nós e conexões de uma rede hipertextual são heterogêneos" (p. 25), uma vez que podem ter associações a elementos de qualquer natureza. Isso torna o hipertexto um ambiente aberto e ao mesmo tempo complexo pela amplitude de gêneros encontrados em sua constituição.

Também como propriedade do hipertexto, Lévy indica a Multiplicidade e Encaixe de Escalas, onde todos os nós e conexões de uma rede são potenciais redes, ou seja, uma mudança em um único nó pode influenciar outra rede inteira. Esta propriedade reforça a característica flexível do hipertexto, já que não há uma estrutura pré-definida, podendo uma rede agregar-se a outros nós, ou outras redes, moldando-se em função dos processos nela existentes. 
Já a propriedade denominada de Exterioridade, aponta para o fato de que uma rede não possui uma unidade, sendo diretamente influenciada por fatores externos, mantendo a rede ativa através das diversas intervenções em seus processos provenientes de diferentes situações, bem como potencializando a característica aberta das redes hipertextuais.

A quinta propriedade é chamada Topologia e diz respeito aos caminhos pelos quais a rede se desenvolve. Tendo em vista que "a rede não está no espaço, ela é o espaço” (p. 26), tudo se desenvolve nela, de tal maneira que ela será modificada em função das diferentes requisições, criando novos caminhos numa dinâmica de totalidade da rede, onde tudo acontece e depende dela.

Por fim, o princípio da Mobilidade dos Centros remete à inexistência de nó central. Uma vez que as redes hipertextuais possuem ramificações infinitas, podendo existir diversos nós que assumem o centro dos processos de acordo com as requisições feitas à rede. Esta dinâmica demanda uma constante participação dos nós que a integram, alternando-se em diferentes papéis, instaurando dessa forma uma lógica colaborativa.

Embora o hipertexto seja uma organização independente e anterior à tecnologia, potencializou-se pela presença destes recursos, apresentando-se como uma estrutura reticular essencialmente dinâmica e aberta, uma vez que a rede não pode estagnar tampouco se fechar, dependendo diretamente da atuação dos nós que a compõem. Assim, é uma organização que se caracteriza "por uma tessitura inacabada, permanente, diversificada, emergente, criativa, móvel, significativa, plural, viva" (LÉVY apud LIMA JUNIOR, 2005, p.152).

Desta forma, os conceitos de cibercultura e de hipertexto, contribuem para o entendimento da lógica das redes latente na sociedade contemporânea, onde uma de suas principais características é a alteração das concepções de espaço e tempo, uma vez que, ao conceber o ciberespaço como um novo território onde a comunicação em tempo real é potencializada, a distância geográfica se torna irrelevante, ampliando a área de interação dos indivíduos para uma dimensão global.

A partir disso, parece fundamental propor ambientes que potencializem a manifestação de conhecimentos, a fim de proporcionar a qualquer indivíduo a possibilidade de emissão de informações e a construção de práticas que possam culminar em processos de aprendizagem naturalmente colaborativos e que possam se traduzir em incentivo à inteligência coletiva.

\subsection{A lógica reticular da autoria colaborativa}

Um processo capaz de atender a essa demanda, bem como permitir a expressão e mobilização, é a autoria colaborativa. Esta dinâmica vai ao encontro das especificidades características do coletivo inteligente baseado em estruturas reticulares, apresentando-se também como um meio de estabelecer ou reconfigurar conhecimentos, significados e sentidos a partir da reflexão sobre o saber próprio e do próximo. Além disso, segundo Axt, dentro desses processos são importantes, entre outros aspectos, questões como a negociação, respeito à individualidade, ao tempo e ao limite de cada envolvido (2001, p.136).

Ou seja, a autoria colaborativa constitui uma dinâmica na qual os envolvidos podem assumir livremente diversas funções em busca da ampliação do conhecimento, tanto individual quanto coletivo, a partir de suas próprias experiências, possibilidades e percepções. Assim, além de exercer um papel de criador de subsídios, são estimulados a analisar a importância dos recursos que estão utilizando, bem como explorar diferentes maneiras de aplicação desses meios dentro da perspectiva que melhor contemple o objetivo que pretendem alcançar. 
Parece incoerente com a dinâmica social contemporânea que essas práticas sejam baseadas em uma lógica fechada, portanto limitada, sendo fundamental a vivência de maneiras democráticas de desenvolvimento de processos criativos. Como exemplo, apresenta-se a Filosofia de Software Livre onde, através de uma dinâmica essencialmente colaborativa, qualquer indivíduo pode auxiliar de acordo com suas possibilidades.

Essa Filosofia estabelece um pensamento democrático, primando pela liberdade de conhecimento e expressão, instituindo uma cultura Copyleft, que segundo Lemos (2004), se opõe ao termo Copyright, trazendo o sentido de uma livre transformação de obras com processos de adição e modificação criativa, mantendo a característica livre do mesmo, ou ainda, a apropriação crítica e coletiva de trabalhos.

Desta forma, o software livre apresenta-se como um fenômeno em constante desenvolvimento e crescente utilização nas mais diversas áreas. Sua filosofia é composta de quatro liberdades ${ }^{3}$ básicas que softwares devem seguir, são elas: executar, estudar para adaptação às necessidades, redistribuir e aperfeiçoar obras de qualquer natureza.

Assim, uma obra que segue esta Filosofia nunca estará terminada, pois a infindável possibilidade de aprimoramento e adição de funcionalidades faz com que tanto os recursos tecnológicos quanto os recursos intelectuais possam ser refinados, agregados, explorados e difundidos, promovendo processos criativos que tornam a rede um local de desenvolvimento livre através do reconhecimento do ciberespaço como um ambiente público de expressão de cultura e de reconhecimento da identidade.

A partir dos elementos abordados até então, é possível supor que as tecnologias de rede são capazes de oferecer subsídios a processos baseados em autoria e colaboração, tendo como um de seus aspectos fundamentais a conectividade, já que as constantes (re)conexões e (re)articulações, são processos que impulsionam a expansão das redes, possibilitando o estabelecimento de relações comunicacionais mais ricas e profundas, potencializando outro elemento inerente às tecnologias de rede, a interatividade.

\subsection{A interatividade em processos de autoria colaborativa hipermidial}

O termo "interatividade" surgiu a partir do atendimento a especificidades que o fizeram ser um conceito que transcende a concepção de interação por si só. Essa transmutação de termos ocorreu, principalmente, por influência das tecnologias eletrônicas e digitais, em decorrência da crescente necessidade de transpor os processos comunicacionais tradicionais geralmente baseados em uma estrutura linear.

Segundo Silva (2000, p. 100), uma obra de qualquer natureza, pode ser considerada interativa quando contemplar uma concepção de "complexidade, multiplicidade, não-linearidade, bidirecionalidade, potencialidade, permutabilidade (combinatória) e imprevisibilidade". Estes elementos possibilitam um maior envolvimento por parte dos envolvidos no processo criativo, no sentido de criar e agregar novos conceitos e aspectos em uma dinâmica intensa.

Esses processos interativos podem contar com uma ampliação conceitual da organização hipertextual, a chamada Hipermídia, resultante da união da multimídia com o hipertexto (p.147). A partir desta fusão, Silva propõe que, em uma obra hipermidial, o usuário não só pode escolher os caminhos que irá percorrer em sua estrutura, mas também, alterá-los de forma a criar novas rotas e funcionalidades (p. 149). Sendo assim,

3 Essas liberdades foram definidas pela Free Software Foundation responsável pelo Projeto GNU, pioneiro na filosofia de software Livre. Disponível em: <http://www.gnu.org/philosophy/free-sw.pt.html>. Acesso: fev. 2006. 
uma obra hipermidial nunca estará totalmente finalizada, mas sempre pronta a receber novas entradas e definições.

Complementando o pensamento de Silva, é possível afirmar que em uma obra hipermidial não existe uma linha de raciocínio correta ou fechada, os sujeitos podem tanto ser autores de novos caminhos como co-autores, modificando os caminhos já existentes. Uma obra hipermidial é, em sua essência, interativa e oferece recursos libertários e exploratórios, transcendendo para uma lógica de raciocínio e ação autônoma e ao mesmo tempo reticular. (p. 154).

\subsection{A inclusão digital na sociedade em rede}

Tendo em vista os desdobramentos deste contexto, percebe-se que grande parte dos indivíduos se encontra fora da lógica da Sociedade em Rede, uma vez que raramente assume o papel de nó ativo nas redes as que pertencem, possivelmente em função da falta de oportunidades ou até mesmo pela tradicional passividade decorrente de uma cultura de reprodução e recepção. Assim, os sujeitos sofrem mais uma forma de segregação social, uma vez que o processo de virtualização e de conexão generalizada da atualidade, exige que os indivíduos possam mover-se no ciberespaço na condição de cidadãos, não sendo suficiente o acesso às tecnologias digitais em uma perspectiva reprodutora e hierarquizada.

A partir disso, observa-se a necessidade de processos que possam estimular a criação de uma cultura com vistas à pró-atividade e à apropriação crítica e criativa das tecnologias de rede, potencializando dinâmicas de aprendizagem baseadas na colaboração, através do estabelecimento de práticas que venham promover Inclusão Digital, nas quais a questão principal não seja simplesmente proporcionar o acesso à tecnologia, mas sim, considerar a importância de que os indivíduos interajam de maneira criativa e dinâmica, para que se adquira, sobretudo, a "capacidade livre de apropriação dos meios, que não só da técnica, mas sociocognitiva”. (LEMOS, 2003b, p.2).

Assim, uma das dimensões dos processos de inclusão digital, é o reconhecimento da potencialidade autoral do indivíduo e das tecnologias de rede enquanto ambientes comunicacionais, respeitando a diversidade advinda dessa dinâmica e comprometendo-se com todo o processo. Assim, a inclusão passa de uma simples correlação instrumental de entendimento dos significados encontrados nas redes, para um processo ativo que caminha em direção à aceitação e à colaboração, "capaz de operar transformações estruturais passíveis de deslocar os modos de efetuar as distinções de si e do mundo". (MARASCHIN, 2005, p.140).

Neste sentido, o processo de inclusão digital parte, sobretudo, de assumir-se como nó em constante ação dentro da estrutura reticular na qual está inserido, atuando na construção de uma fluência tecno-conceitual, que se institui na "apropriação críticoreflexiva dos fenômenos sóciotecnicos numa perspectiva de contextualização sociocultural, bem como o desenvolvimento e a manutenção das habilidades necessárias à interação com e através deles". (TEIXEIRA, 2006, p.25).

Esse processo é dinâmico, provisório e renovado na rede a cada instante, ou seja, uma vez que a rede é reorganizada, os nós são alterados pela rede, possibilitando a vivência de processos mais complexos.

Diante de todos os aspectos abordados até então e de suas implicações nos processos sócio-tecnológicos, percebe-se a necessidade de ambientes virtuais que possam explorar as características das tecnologias de redes, especialmente os recursos hipermidiais. Ambientes capazes de atender à necessidade de criação de novos territórios no ciberespaço, onde se possa efetivar o fortalecimento da cultura, o exercício da autoria colaborativa, e que, além de constituir alternativas à crescente demanda por 
processos de inclusão digital, possibilitem a qualquer indivíduo assumir-se como nó ativo na dinâmica das redes e numa perspectiva que o autorize a, cada vez mais, participar da estrutura reticular que permeia a Cibercultura.

\section{Definições do ambiente e metodologia de desenvolvimento}

Com base nesta contextualização, desenvolveu-se um ambiente hipermidial de autoria colaborativa, denominado criAtivo $^{4}$, que procura se apropriar das características reticulares das tecnologias digitais. Seu principal objetivo é apresentar uma alternativa à demanda por processos criativos de inclusão digital na cibercultura, propiciando a vivência de experiências de aprendizagem ricas e profundas.

Assim, o protótipo desenvolvido, é um ambiente virtual de aprendizagem onde são constituídas comunidades virtuais, com vistas ao desenvolvimento de processos hipermidiais de construção de projetos didáticos multimídia ${ }^{5}$ de maneira coletiva, visando oferecer meios que possam auxiliar em estratégias de ensino, como por exemplo, construção de histórias e tutoriais multimídia, entre outras práticas que utilizem as tecnologias de rede, como suporte a processos de interação e colaboração com vistas à aprendizagem.

O ambiente possui caráter essencialmente hipermidial, no sentido de que cada grupo poderá se apropriar dos recursos e possibilidades da maneira que melhor se adaptar aos objetivos do projeto em construção. Tal dinâmica também é considerada nos produtos construídos dentro do ambiente. Salienta-se que cada comunidade pode conter diversos projetos (Figura 1, Detalhe A) e apresenta a lista de autores cadastrados naquele projeto, bem como se estes estão online no momento (Figura 1, Detalhe B).

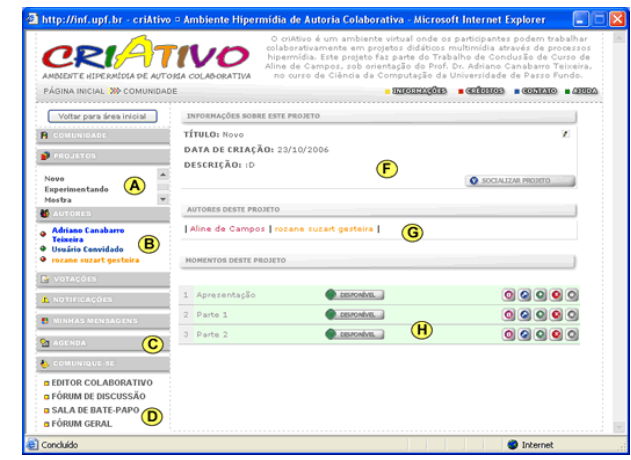

Figura 1 - Momentos de um Projeto Didático Multimidial

Além disso, a fim de contemplar elementos inerentes ao processo de aprendizagem, foram introduzidos meios que pudessem oferecer suporte à contínua negociação entre os autores, bem como à reflexão acerca dos recursos e da prática de construção colaborativa.

No ambiente, o indivíduo pode se inscrever nas comunidades que deseja interagir como "Autor", onde participa das diversas atividades e do desenvolvimento do projeto sempre numa perspectiva horizontal. Também pode criar comunidades, assumindo o status de "Desafiador", discussões e as ações, mas por atuar como estimulador do grupo em uma dinâmica de rede, participando das negociações acerca da adição de novos membros à comunidade,

\footnotetext{
${ }^{4}$ Disponível em http://inf.upf.br/ 55585/criativo - Usuário: convcria - Senha: c0nv1

${ }^{5}$ Entendidos como projetos idealizados, conceituados e desenvolvidos no ambiente, com vistas à potencialização de processos de aprendizagem.

${ }^{6}$ O termo é adotado no sentido de identificar o indivíduo que desafia à criação coletiva, à agregação social, bem como à solução coletiva de um processo, além de propor interações, desafios e antever demandas.
} 
bem como na manutenção da fidelidade da comunidade às características reticulares nas quais se baseia.

Como já mencionado, para ingressar em uma comunidade dentro do Ambiente, é necessário efetuar uma inscrição com uma breve justificativa de seu interesse em participar de um projeto específico. Essas informações serão recebidas pelo Desafiador, que através de um uma negociação com os demais membros irá aceitar ou negar a participação do novo integrante.

Essa sistematização nas comunidades foi implementada para reforçar as características abertas e principalmente democráticas do ambiente, uma vez que todos os autores poderão expor suas opiniões a respeito das ações dentro da comunidade, fazendo com que esta não tenha um elemento centralizador, mas sim vários centros móveis indo ao encontro da lógica hipertextual.

Algumas formas de comunicação como fórum de discussão, sala de bate-papo, editor colaborativo e mensagens particulares, foram oferecidas no ambiente. Esses recursos são meios de reforçar as relações entre os diversos participantes de maneira facilitada e aberta, além de expandir a discussões e reflexões acerca de todo o processo de construção colaborativa dos projetos. Ressalta-se que algumas dessas ferramentas estão disponíveis também dentro das comunidades, como suporte comunicacional específico das mesmas (Figura 1, Detalhe D).

Dentro da comunidade, as ações sobre o projeto didático são constituídas a partir de módulos de desenvolvimento chamados de "Momentos" (Figura 1, Detalhe H), sendo estes as diferentes unidades do projeto didático. Os Momentos são criados pelos participantes da comunidade da maneira que decidirem ser conveniente a partir das trocas efetuadas e suportadas pelas ferramentas de comunicação disponíveis. Assim, os autores poderão trabalhar simultaneamente, porém em módulos diferentes devido à questão de integridade referencial e atualização do projeto. Há também uma área destina a identificação dos autores específicos daquele projeto (Figura 1, Detalhe G) e também as informações referentes a este (Figura 1, Detalhe F).

O principal recurso oferecido dentro do ambiente trata-se da ferramenta de desenvolvimento dos Momentos dos projetos didáticos multimídia (Figura 2). Esta funcionalidade conta com uma base de dados com recursos multimídia, sendo que a essa pode ser ampliada através de um mecanismo de upload categorizado de arquivos, sendo que os recursos inseridos por um participante de determinado projeto estão disponíveis a todas as outras comunidades, numa dinâmica colaborativa.

Procurou-se estabelecer no ambiente o suporte a recursos que possam ser (re)arranjados numa perspectiva não-linear, que possibilite a exploração de suas funcionalidades e possam ser combinadas de maneira a criar diferentes caminhos na construção dos projetos didáticos. Assim, os participantes podem tanto constituir novas ações dentro do projeto, quanto realizar modificações em ações já estabelecidas anteriormente. 


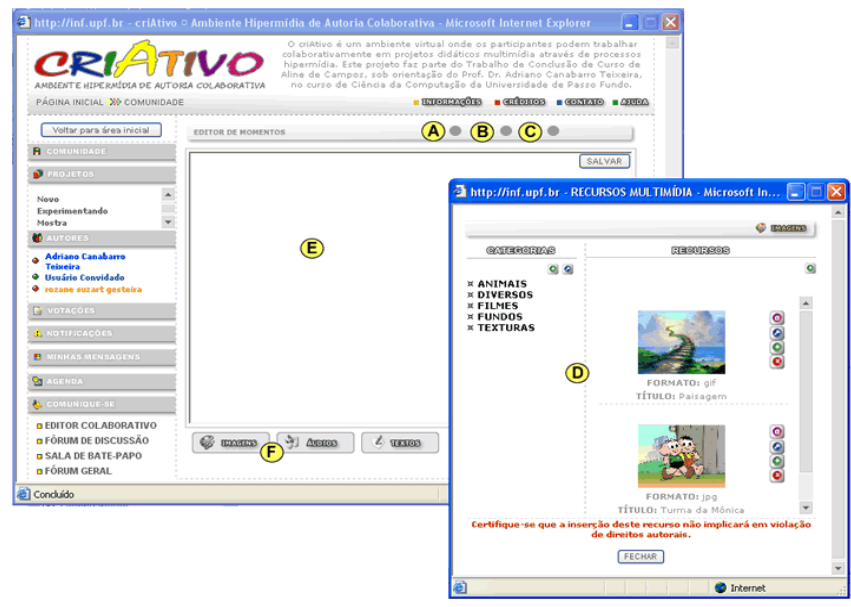

Figura 2 - Aspectos do editor de Momentos

Esses recursos estão divididos inicialmente em três categorias, sendo elas imagens, áudios e textos que serão disponibilizados (Figura 2, detalhe F). Escolhendo um destes recursos se pode visualizar as categorias de elementos inseridos no repositório multimídia. Além disso, também é possível a execução desses arquivos numa forma de pré-vizualização de seu conteúdo (Figura 2, detalhe D).

Há uma grande área destinada a livre construção do Momento (Figura 2, detalhe E). Ainda, o ambiente oferece suporte ao armazenamento de diferentes versões (Figura 2, detalhe C) de um mesmo Momento, ou seja, o autor poderá salvar uma versão na qual está trabalhando e, posteriormente, realizar diversas mudanças, caso considere que a versão anterior estava mais adequada à idéia da comunidade, poderá facilmente retornar, atribuindo a esta o status de versão atual. Em decorrência dessa funcionalidade, as experimentações podem se tornar mais livres uma vez que há uma garantia de recuperação do trabalho realizado até então.

Aos módulos dos projetos didáticos, também foram agregados recursos de armazenamento de ações realizadas (Figura 2, detalhe B), mantendo assim um histórico das atividades executadas, bem como os autores responsáveis por estas. Em qualquer fase do desenvolvimento, é possível a visualização do projeto na íntegra, onde o autor pode adquirir uma visão geral do processo de maneira a detectar mais facilmente correções a serem realizadas, estabelecer a criação de novos módulos, bem como modificar elementos do projeto (Figura 2, detalhe A).

Os projetos didáticos que forem considerados aptos à distribuição de acordo com os autores envolvidos, podem ser disponibilizados no próprio ambiente para acesso por parte de qualquer autor independente das comunidades nas quais estiver vinculado. Assim, estes podem ser tanto utilizados em processos de aprendizagem, quanto apropriado por outro grupo que possa lhes dar continuidade, implementando novas funcionalidades ou modificando criativamente as já existentes.

\section{Base teórico-conceitual do criAtivo}

A começar pela concepção do ambiente, percebe-se que este vai ao encontro das características da Cibercultura, uma vez que pretende possibilitar a reformulação de métodos tradicionais de construção de práticas didáticas e exercícios de aprendizagem, possibilitando o desenvolvimento conjunto de projetos hipermidiais suportados pelas tecnologias de rede, contemplando assim a Lei da Reconfiguração.

A fim de considerar também, a Lei da Liberação dos Pólos de Emissão, qualquer indivíduo poderá se tornar parte dos processos de autoria constituídos dentro do 
ambiente, tendo assim a possibilidade de exprimir suas idéias e percepções. Essa característica é fortemente considerada, uma vez que o criAtivo é organizado em uma lógica que dá suporte à comunicação multidirecional e democrática.

Também, em relação à Lei da Conexão Generalizada, o protótipo proporcionará o rompimento espaço-temporal, em se tratando de um ambiente que utilizará o ciberespaço como meio, a participação dos indivíduos não estará condicionada a horário ou espaços específicos.

Unindo-se a essas características, os princípios do Hipertexto também serão considerados na definição do protótipo, uma vez que se tratam de elementos importantes tanto no que diz respeito à concepção hipermidial que o ambiente pretende assumir, quanto para que este possa se constituir de fato em um ambiente marcado pela lógica das redes.

A possibilidade de instaurar processos de autoria colaborativa é o principal foco do ambiente, uma vez que se trata de estabelecer práticas que possam fortalecer a inteligência coletiva e propiciar uma vivência democrática no que diz respeito tanto aos aspectos comunicacionais quanto criativos.

Além disso, o ambiente segue a Filosofia de Software Livre a fim de estimular seu contínuo desenvolvimento, uma vez que não se tratará de uma obra pronta e fechada. Sendo assim, qualquer indivíduo poderá modificar, adicionar ou retirar ferramentas da maneira que necessitar, a fim de que o ambiente, ou os projetos nele desenvolvidos, possam atender às novas demandas que surgirem no decorrer de sua utilização. Em se tratando de um ambiente que será desenvolvido fortemente baseado na lógica reticular, os elementos mais marcantes serão a Interatividade e a Hipermídia, além da Conectividade, que se apresenta como um grande potencializador dos demais elementos.

No que diz respeito à Interatividade a ser oferecida no ambiente, pretende-se implementar os conceitos propostos por Silva (2000), a fim de que possam se estabelecer como elementos norteadores no desenvolvimento dos recursos a serem oferecidos. Também, a fim de auxiliar nesse processo de implementação de um grau de interatividade que atenda às demandas nascidas da fundamentação teórica, optou-se pelo conceito de hipermídia na construção dos projetos didáticos.

Assim, pretende-se que o ambiente possa ser utilizado por qualquer grupo de forma livre, interativa e colaborativa, possibilitando que, além de receptores, estes sejam emissores de conhecimento e desta maneira, tornem-se elos de comunicação plena na Sociedade em Rede e por consequiência, sujeitos de um processo de Inclusão Digital.

\section{Considerações parciais}

Através das reflexões realizadas acerca dos elementos da Sociedade em Rede surgidas a partir da revisão bibliográfica, considera-se imprescindível o atendimento à emergência por alternativas de Inclusão Digital que possam constituir processos de aprendizagem apoiados em construção de práticas criativas, essencialmente colaborativas e capazes de fomentar em seus participantes mudanças no que diz respeito à sua importância dentro desses processos, assumindo, a partir disso, uma postura pró-ativa.

Tendo em vista estes fatos, espera-se identificar pontos relevantes nesse processo de mudança de postura por parte dos envolvidos, verificando como se dará a apropriação de conhecimento através da utilização do ambiente, bem como a influência dos elementos estudados neste trabalho em relação às práticas adotadas com vistas a inclusão digital. 


\section{Referências Bibliográficas}

AXT, Margarete. et al. (2001) "Era uma vez..: co-autoria em narrativas coletivas intersecionadas por tecnologias digitais", In: XII Simpósio Brasileiro de Informática na Educação: Educação a Distância Mediada por Computador, Vitória - ES. ANAIS SBIE-2001. UFES, v. 1. p. 136-144.

CASTELLS, Manuel. (1999) “Sociedade em Rede”. Paz e Terra, São Paulo.

FREE SOFTWARE FOUNDATION. The GNU Project. Disponível em: <http://www.gnu.org/philosophy/free-sw.pt.html>. Acesso: mar. 2006.

LEMOS, A. (2003a) "Cibercultura: Alguns pontos para compreender a nossa época". In: LEMOS, A.; CUNHA, Paulo (orgs). Olhares sobre a Cibercultura. Sulina, Porto Alegre. p.11-23.

LEMOS, A. (2003b) "Dogmas da Inclusão Digital". Disponível em: $<$ http://www.facom.ufba.br/ciberpesquisa/lemos/artigos.html>. Acesso em: out. 2005.

LEMOS, A. (2004) "Cibercultura e Identidade Cultural: Em direção a uma cultura copyleft?" em: $<$ http://www.facom.ufba.br/ciberpesquisa/lemos/artigos.htm>. Acesso: fev. 2005.

LÉVY, Pierre. (1993) “Tecnologias da Inteligência”. Editora 34, São Paulo.

LÉVY, Pierre. (2003) "A Inteligência Coletiva: Por uma antropologia do ciberespaço" 4.ed. Loyola, São Paulo.

LIMA JUNIOR, Arnaud S. de (2005) "Tecnologias inteligentes e educação: currículo hipertextual”. Quartet, Rio de Janeiro.

MARASCHIN, Cleci. (2005) "Redes de Conversação como operadoras de mudanças estruturais na convivência", In: Pellanda, Nize Maria Campos; Schlünzen, Elisa Tomoe Moriya; Schlünzen Junior, Klaus. Inclusão digital: tecendo redes afetivas/cognitivas. DP\&A, Rio de Janeiro.

SILVA, Marco. (2000) "Sala de Aula Interativa”. Quartet, Rio de Janeiro.

TEIXEIRA, A. C. (2005) "Formação Docente e Inclusão Digital: a análise do processo de emersão tecnológica de professores". Tese (Doutorado em Informática na Educação) - Programa de Pós Graduação em Informática na Educação da Universidade de Federal do Rio Grande do Sul, Rio Grande do Sul, 2005. 